\title{
EDITORIAL
}

\section{Should primary angioplasty be available for all patients with an ST elevation myocardial infarction?}

Heart 2005;91:1509-1511. doi: 10.1136/hrt.2004.059485

For the acute myocardial infarction patient, percutaneous coronary intervention is clearly superior to thrombolysis for many clinical end points, yet widespread availability of PCI services is still far from being realised

.

- has less reinfarction

- leads to a shorter hospital stay

- has less hospital readmission

- causes less heart failure

- leads to less angina

- causes less strokes.

The overall combined end point (death, reinfarction, and stroke) was $8 \%$ for primary PCI versus $14 \%$ for thrombolysis $(p<0.0001) .{ }^{1}$

\section{WHAT HAPPENS TO PATIENTS OVER THE LONG TERM?}

The pioneering Zwolle group whose randomised trial between PCI and thrombolysis in noncardiogenic shock ST elevation myocardial infarction (STEMI) patients reported five year mortality rates of $13 \%$ versus $24 \%$, respectively $(\mathrm{p}<0.01)$, with a reduction in non-fatal MI $(6 \%$ $v 22 \%$ ), recurrent ischaemia, and heart failure with no differences in overall costs. These Kaplan-Meier curves were divergent showing an increased benefit with time. ${ }^{2}$

In this issue of Heart, Parodi and colleagues ${ }^{3}$ publish their five year outcome data for patients undergoing primary coronary intervention for acute ST elevation MI (all ages and including cardiogenic shock) in a single centre. ${ }^{3}$ The door to balloon time was a remarkable mean (SD) 22 (15) minutes, which shows what can be achieved with good organisation and communication. The five year mortality of $20 \%$ after five years is all the more extraordinary when a comparison is made with a thrombolysis driven service giving comparable mortality at 30 days. $^{4}$

Why has there been such reluctance to implement what seems to be a superior treatment for a common life threatening condition? A cursory glance of the medical literature will find many examples whereby evidence is ignored in favour of accepted, though flawed, dogma.

\section{PCI VERSUS EARLY THROMBOLYSIS}

Pre-hospital thrombolysis delays the time of onset of symptoms by $33^{5}$ to $55^{6}$ minutes, and the mortality benefits for patients treated within 60 minutes of onset of chest pain was significant.

The CAPTIM investigators compared a strategy of pre-hospital thrombolysis with transfer to an interventional facility for primary PCI. Patients randomised $<2$ hours from symptom onset

Abbreviations: AMl, acute myocardial infarction; $\mathrm{PCl}$, percutaneous coronary intervention; STEMI, ST elevation myocardial infarction; TIMI, thrombolysis in myocardial infarction \\ Correspondence to: Brighton and Sussex University Hospitals, East Sussex BN2 5BE, UK; adam.debelder@ bsuh.nhs.uk}

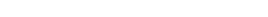

\begin{abstract}
- saves lives in the short and long term
- leads to better TIMI III flow in the infarct related artery

The two strategies available to achieve been pitched against each other as to which is best treatment. An evaluation of the intravenous thrombolytic treatment have shown that the PCI strategy:
\end{abstract}


showed a trend toward lower 30 day mortality in the prehospital thrombolysis group $(2.2 \% \vee 5.7 \%)(\mathrm{p}=0.05)$, and the mortality for patients treated $>2$ hours was similar $(5.9 \% v 3.7 \%)(\mathrm{p}=0.47) .{ }^{7}$ It is fair to conclude that PCI does not confer any mortality benefit over thrombolysis that is given within $<2$ hours of chest pain onset.

\section{WHAT ABOUT IN THE REAL WORLD?}

This is fine for those places that have the facilities, but what about the real world where scarce resources make this option an impossibility?

The DANAMI-2 study examined whether transfer of patients to a PCI centre would still offer patient benefit1572 patients were randomised to PCI $(\mathrm{n}=790)$ or intravenous alteplase given on admission $(n=782)$. All transfers were made within three hours. The primary end point (mortality, reinfarction, disabling stroke at 30 days) was $14.2 \%$ in the thrombolysis group versus $8.5 \%$ in the primary PCI group $(\mathrm{p}=0.002)$, the majority of the benefit being from prevention of reinfarction. ${ }^{8}$

The Czech Republic have harnessed their resources and now provide a 24 hour PCI service for AMI throughout the country, and yet they only have 22 catheter laboratories. Their management strategy is based on the PRAGUE 2 triala randomised controlled study comparing long distance travel for PCI versus thrombolysis in the nearest available hospital $(\mathrm{n}=850)$. The study was stopped prematurely because of a 2.5 -fold excess mortality in the thrombolysis group among patients treated $>3$ hours after the onset of symptoms ( $15.3 \%$ thrombolysis $v 6 \% \mathrm{PCI}$ ); however there was no significant difference between the strategies if the patient was treated $<3$ hours from symptom onset."

\section{WHY SHOULD THROMBOLYSIS BE MUTUALLY EXCLUSIVE OF A PCI SERVICE?}

The PRAGUE study examined three strategies for PCI for patients presenting with STEMI to a district hospital without on-site catheterisation facilities-immediate thrombolysis, thrombolytic treatment during transfer for PCI, and transfer for primary angioplasty. The combined end point of death, reinfarction, or stroke was reached in $23 \%, 15 \%$, and $8 \%$ of patients, respectively. ${ }^{10}$

The timing and delivery of glycoprotein IIb/IIIa inhibitors before PCI for STEMI has improved results, ${ }^{11-13}$ but the delivery of these agents is not straightforward in the prehospital setting.

Perhaps, this so-called facilitated angioplasty with thrombolysis \pm glycoprotein IIb/IIIa inhibitors may have a role, particularly for patients who may have to travel long distances for their PCI. The outcome of trials such as FINESSE and ASSENT IV will provide the answer, but I would be surprised if these strategies will provide such striking differences that the investment of expensive drugs combined with intervention will become routine.

\section{THROMBOLYSIS WITH BACKUP PCI}

What about a strategy of thrombolysis with backup PCI for those patients in whom chest pain or ECG changes persist? This is the default position of many units, which dramatically reduces the number of patients requiring PCI in the short term. The randomised trials are not fully clear on the best course of action-there is a suggestion that late PCI may have some benefit, but only if the intervention is successful. ${ }^{14}$

Most patients that survive a STEMI subsequently undergo angiography and revascularisation at later date; why not do it at the time the data strongly shows is the best time for PCI to occur-as soon after the acute occlusion as possible?

\section{PRIMARY PCI: MOVING FORWARDS}

Indeed for those involved in primary PCI, the debate has moved on. Previous studies have established the benefit of stenting over plain old balloon angioplasty, mainly for the benefit of recurrent angina. Parodi and his colleagues ${ }^{3}$ have analysed their data to discuss the role of glycoprotein IIb/IIIa inhibitors, appropriateness and timing of non-culprit coronary lesion treatment, and the provision of a risk stratification score based on simple clinical criteria. In most catheter laboratories patients are undergoing PCI for lesions causing stable angina-a procedure that confers little or no prognostic benefit; yet the patients with STEMI for whom this procedure has proven prognostic benefit are denied it. Our priorities need to refocus.

\section{ARE THERE ENOUGH INTERVENTIONAL CARDIOLOGISTS?}

To reproduce Parodi's results, primary PCI should be performed at facilities that undertake a sufficient volume of work to develop and maintain skills. ${ }^{15}$ The American College of Cardiology/American Heart Association guidelines suggest that institutions performing PCI should be doing at least 400 cases a year with a 24 hour capability. ${ }^{16}$ To my mind, if a patient can reach such a PCI facility within two hours of arrival of the emergency services, reorganisation of regional strategies should take place to facilitate this. For those areas where this is currently an impossibility, regional discussions should take place to decide where such a centre could be developed.

Many centres are embracing this challenge, but there remain manpower issues which need to be grasped, understood, and dealt with if PCI is to become a routine procedure.

\section{“WE CAN'T DO AN ANGIOPLASTY - IT WILL AFFECT OUR DOOR TO NEEDLE TIMES"}

Most units are highly efficient in the delivery of thrombolysis to patients coming through the hospital door, yet, paradoxically, protocols such as this can become barriers to change. The measurement of door to needle times has some bearing on the patient's outcome, but unless the crucial time measurement of onset of symptoms becomes the yardstick, the patient may well end up with the wrong treatment-all decisions should be based on the onset of the infarct, and not the time medical care starts.

\section{WHAT IS THERE TO DO?}

- The most significant delay contributing to delays in treatment for STEMI is the time it takes for the emergency services to be called by the patient and their family. The average time for pain to call time is one hour. Media campaigns have made little difference in reducing this, but the message that chest pains require immediate contact with the emergency services needs to be hammered home.

- Establish a local high volume PCI centre if one is not available.

- Once contact is made with the patient, the main purpose is to establish an ECG diagnosis and make an immediate strategy for treatment by contacting the local AMI coordinator.

- Data from the various travelling trials for STEMI PCI have shown that the visit to the local hospital engenders a 3050 minute delay. Therefore, it is no longer acceptable for patients with STEMI to be transferred to the most local hospital, but to one that delivers the best treatment.

\section{REFERENCES}

1 Keeley EC, Boura JA, Grines CL. Primary angioplasty versus intravenous thrombolytic therapy for acute myocardial infarction: a quantitative review of 23 randomised trials. Lancet 2003;361:13-20. 
2 Zijlstra F, Hoorntie JCA, de Boer M, et al. Long-term benefit of primary angioplasty as compared with thrombolytic therapy for acute myocardial infarction. N Engl J Med 1999;341:1413-9.

3 Parodi G, Memisha G, Valenti R, et al. Five year outcome after primary coronary intervention for acute ST elevation myocardial infarction: results from a single centre experience. Heart 2005:91:1541-4.

4 Mahon NG, O'Rorke C, Codd MB, et al. Hospital mortality of acute myocardial infarction in the thrombolytic era. Heart 1999;81:478-82.

5 Weaver WD, Cerqueira M, Hallstrom AP, et al. Prehospital-initiated vs hospital-initiated thrombolytic therapy. The myocardial infarction triage and intervention trial. JAMA 1993;270:1211-6.

6 European Myocardial Infarction Project Group. Prehospital thrombolytic therapy in patients with suspected acute myocardial infarction. The European myocardial infarction project group. $N$ Engl J Med $1993 \cdot 329 \cdot 383-9$

7 Steg PG, Bonnefoy E, Chabaud S, et al. Impact of time to treatment on mortality after prehospital fibrinolysis or primary angioplasty: data from the CAPTIM randomized clinical trial. Circulation 2003;108:2851-6.

8 Andersen HR, Nielsen TT, Rasmussen K, et al. A comparison of coronary angioplasty with fibrinolytic therapy in acute myocardial infarction. N Engl J Med 2003;349:733-42.

9 Widimsky P, Budesinsky T, Vorac D, et al. Long distance transport for primary angioplasty vs immediate thrombolysis in acute myocardial infarction: final results of the randomized national multicentre trial-PRAGUE-2. Eur Heart 2003:24:94-104

10 Widimský P, Groch L, Zelízko M, et al. Multicentre randomized trial comparing transport to primary angioplasty vs immediate thrombolyis vs combined strategy for patients with acute myocardial infarction presenting to a community hospital without a catheterization laboratory. The PRAGUE study. Eur Heart J 2000;21:823-31.

11 Montalescot G, Barragan P, Wittenberg O, et al. Platelet glycoprotein Ilb/Illa inhibition with coronary stenting for acute myocardial infarction. N Engl J Med 2001:344:1895-903.

12 Stone GW, Grines CL, Cox DA, et al. Comparison of angioplasty with stenting, with or without abciximab, in acute myocardial infarction. N Engl J Med 2002;346:957-66.

13 Montalescot G Borentain M, Payot L, et al. Early vs late administration of glycoprotein $\mathrm{Ilb} / \mathrm{llla}$ inhibitors in primary percutaneous coronary intervention of acute ST-segment elevation myocardial infarction: a meta-analysis. JAMA 2004;292:362-6.

14 Sutton AG, Campbell PG, Graham R, et al. A randomized trial of rescue angioplasty versus a conservative approach for failed thrombolysis in STsegment elevation myocardial infarction: the Middlesborough early revascularisation to limit infarction (MERLIN) trial. J Am Coll Cardiol 2004;44:287-96

15 Canto JG, Every NR, Magid DJ, et al. The volume of primary angioplasty procedures and survival after acute myocardial infarction. N Engl J Med 2000;342: 1573-80

16 Smith SC Jr, Dove JT, Jacobs AK, et al. ACC/AHA guidelines of percutaneous coronary interventions (revision of the 1993 PTCA guidelines)-executive summary. A report of the American College of Cardiology/American Heart Association task force on practice guidelines (committee to revise the 1993 guidelines for percutaneous transluminal coronary angioplasty). J Am Coll Cardiol 2001;37:2215-39.

\section{IMAGES IN CARDIOLOGY}

\section{An unusual cause of syncope}

A 65 year old man was admitted to our hospital for recurrent syncope. Two years before presentation, he had placement of a Le Veen shunt for an intractable ascite complicating liver cirrhosis. On physical examination he appeared well. His blood pressure was 130/80 $\mathrm{mm} \mathrm{Hg}$ and heart rate was 85 beats/min. No sign of congestion or cardiac murmur was noticed and an ECG showed a normal sinus rhythm without abnormalities. Transthoracic echocardiogram detected a $3 \times 8 \mathrm{~cm}$ floating fluid filled mass in the right atrium that prolapsed into the right ventricle at each cardiac cycle. Transoesophageal echocardiography indicated that the mass was an intracardiac pseudocyst and was attached to the venous tip of the shunt (panel A). Pulmonary perfusion lung scan did not reveal signs of pulmonary embolism. The patient underwent open heart surgery and the cavitary ascitic fluid filled mass was removed completely (panel B). Histologic examination confirmed that the wall of the pseudocyst comprised fibrin, red blood cells, mononuclear cells, and capillaries.

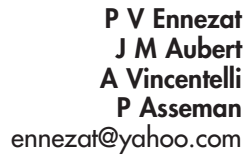

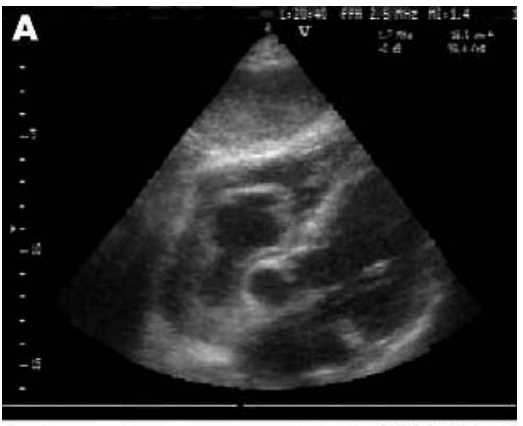
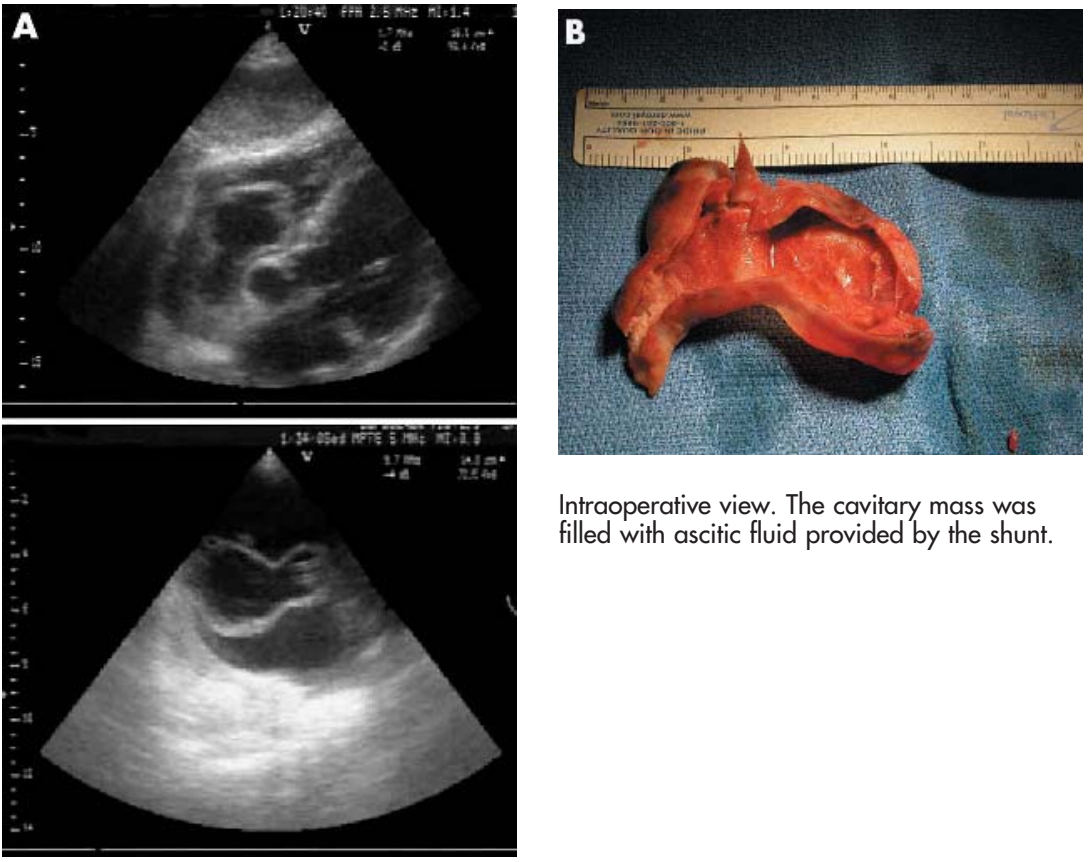

Intraoperative view. The cavitary mass was filled with ascitic fluid provided by the shunt.

Top: Transthoracic echocardiographic subcostal view showing a bilobal mass in the right atrium that appeared to be filled with fluid. Bottom: Transoesophageal echocardiographic view showing that the right atrial mass was attached to the venous tip of the peritonealvenous shunt. 